\title{
Localization and Electrical Characterization of Interconnect Open Defects
}

\author{
Rosa Rodríguez-Montañés, Daniel Arumí, Joan Figueras, Member, IEEE, Willem Beverloo, \\ Dirk K. de Vries, Member, IEEE, Stefan Eichenberger, and Paul A. J. Volf, Member, IEEE
}

\begin{abstract}
A technique for extracting the electrical and topological parameters of open defects in process monitor lines is presented. The procedure is based on frequency-domain measurements performed at both end points of the line. The location as well as the resistive value of the open defect are derived from attenuation and phase shift measurements. The characteristic defect-free impedance of the line and its propagation constant are considered to be unknowns, and their values are also derived from the above measurements. In this way, the impact of process parameter variations on the proposed model is diminished. The experimental setup required to perform the characterization measurements and a simple graphical procedure to determine the defect and line parameters are presented. Experimental results show a good agreement between the predicted location of the open and its real location, found by optical beam induced resistance change inspection. Errors smaller than $2 \%$ of the total length of the line have been observed in the experiments.
\end{abstract}

Index Terms-Metal lines, open defect, process monitors, transmission lines.

\section{INTRODUCTION}

$\mathbf{O}$ PEN defects are responsible for a high percentage of failures in interconnect lines and, as a consequence, are becoming a frequent defect type affecting present complementary metal-oxide-semiconductor (CMOS) integrated circuits [1]-[5]. A break may occur during some of the manufacturing process steps, causing a discontinuity at any physical line otherwise designed to electrically connect the two endpoints (nodes) of the line. This discontinuity may completely eliminate the electrical connection between the nodes if the open defect totally breaks the conductivity of the line. In this case, the open is said to be a strong or full open. On the other hand, if the break is not able to completely disconnect the nodes at both ends of the line, the open is said to be a resistive or weak open.

Defect sources are identified by means of test structures in order to optimize the manufacturing process [6]. Furthermore,

Manuscript received June 07, 2007; revised November 05, 2009. Current version published February 03, 2010. This work was supported in part by MCyT and FEDER projects TEC2007-66672 and TEC2005-01027.

R. Rodríguez-Montañés, D. Arumí, and J. Figueras are with the Departament d'Enginyeria Electrònica (UPC), Barcelona 08028, Spain (e-mail: rosa@eel. upc.edu; arumi@eel.upc.edu; figueras@eel.upc.edu).

W. Beverloo, S. Eichenberger, and P. A. J. Volf are with NXP Semiconductors, 6534 AE Nijmegen, The Netherlands (e-mail: willem.beverloo, stefan. eichenberger, paul.volf@nxp.com).

D. K. de Vries is with NXP Semiconductors, 38926 Crolles Cedex, France (e-mail: dirk.de.vries@nxp.com).

Color versions of one or more of the figures in this paper are available online at http://ieeexplore.ieee.org.

Digital Object Identifier 10.1109/TSM.2009.2039187 an accurate critical area model for random defects is a key issue for the estimation of yield loss sensitivity of products to such random failure mechanisms [7]. Traditionally, conventional test monitors such as the comb-meander-comb structure [8], [9] have been used to characterize the resistive distribution of open defects [10] and bridging defects [11], both of which are the main contributors to yield loss in wiring structures. Other test structures such as nest structures [12], [13] and double bridge test structures [8] have been proposed to evaluate defect size distributions and to estimate yields. Test structures that use the same electrical test equipment as standard chips (digital testers for boundary pads) to locate defect areas have been proposed [14], [15]. Test monitors equipped with site addressable test structures [16] allowing the defect substructure to be identified through electrical measurements also have been proposed. More complex methods to accurately localize defects by voltage contrast techniques using scanning electron microscopy have been presented in [17]-[21].

The advantages of the comb-meander-comb structure lie in its simplicity and in the reduced number (three or four) of pads needed to make dc measurements for the characterization of target defects. In this way, the maximum possible area is provided to the test structure. However, the dc resistance characterization method is not able to locate open defects in the meander-shaped string. The information related to the approximate location of the defect on the line can be very useful, for instance, in the detection of persistent process problems and in failure analysis procedures. Furthermore, reducing the time required to find the location of these defects may have an important impact on the resources devoted to manufacturing process improvement.

Quiescent current measurement based methods used to characterize the open resistance distribution introduce a nonnegligible uncertainty in the computed final value. Indeed, as reported in [10], the resistance of fault-free meander structures used as monitors in this work varies between $2 \%$ and $4 \%$ from its expected (nominal) value. This variation may introduce an uncertainty for weak opens on the order of tens of $k \Omega$. During the test pattern generation for delay testing techniques, such a resistive uncertainty, when applied to typical interconnect structures, may lead to unpredictable test results. Thus, a more precise characterization of open defects may help to better understand this common failure mechanism.

In this paper, a new method based on frequency-domain measurements of the process monitor lines is proposed. The measurements are analyzed and a method for the location of the 


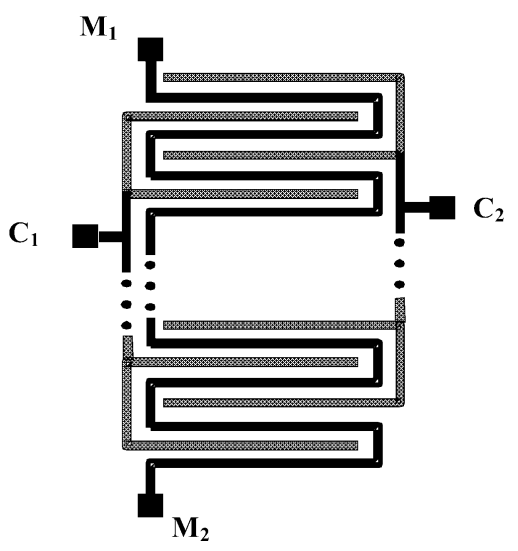

Fig. 1. Comb-meander-comb test structure. Schematic top view (not to scale).

open proposed. The effect of process parameter variations on the calculated values is also discussed.

This paper is organized as follows. The open defect model is presented in the next section, together with the proposed frequency-domain characterization and the analysis of the defective line behavior. Section III illustrates the application of the proposed technique, and experimental work is presented in Section IV. The scalability of the method is given in Section V, which is followed by the conclusions of this paper.

\section{Open Defects In Monitor Structures}

A well-known defect monitor traditionally used for detecting bridging and open defects is the comb-meander-comb structure [9]. It is basically a long meander-shaped wire as shown in Fig. 1 (from pad $\mathrm{M}_{1}$ to pad $\mathrm{M}_{2}$ in the figure) lying between two combs $\left(\mathrm{C}_{1}\right.$ and $\left.\mathrm{C}_{2}\right)$ made of the targeted layer of the manufacturing process. The length $\mathrm{L}$ of the wire follows from the line/space pitch and the test structure area, which is chosen such that the required defect density resolution is obtained at wafer or lot level. The open defect is modeled as a resistance $R_{o p}$ added to the nominal resistance of the wire $\left(R_{n o m}\right)$ because of the partial or total breaking of the line. In a dc-based measurement, the relationship between the externally applied voltage and the current flowing through the line provides the measured resistance of the wire $\mathrm{R}_{\mathrm{M}}$. The difference between the expected resistance $\mathrm{R}_{\text {nom }}$ and the measured one results in the resistance of the open, i.e., $R_{\mathrm{op}}=\mathrm{R}_{\mathrm{M}}-\mathrm{R}_{\text {nom }}$. As mentioned before, owing to process parameter variations, the $R_{\text {nom }}$ uncertainty introduces an $R_{o p}$ uncertainty too. In addition, the nature of the dc measurement does not allow the extraction of any information related to the location of the defect in the wire.

\section{A. Frequency-Domain Characterization}

To obtain information about the location of the partial break, a frequency-domain characterization of the electrical response of the line is proposed. Fig. 2 illustrates a wire (meander) whose length, width, and height are $\mathrm{L}, \mathrm{W}$, and $\mathrm{H}$, respectively. These geometric data, together with the resistivity of the targeted material and the electrical parameters of the dielectric isolating the line from the substrate and the combs, allow the line to be modeled as a transmission line of length L. Fig. 2 shows a stage of

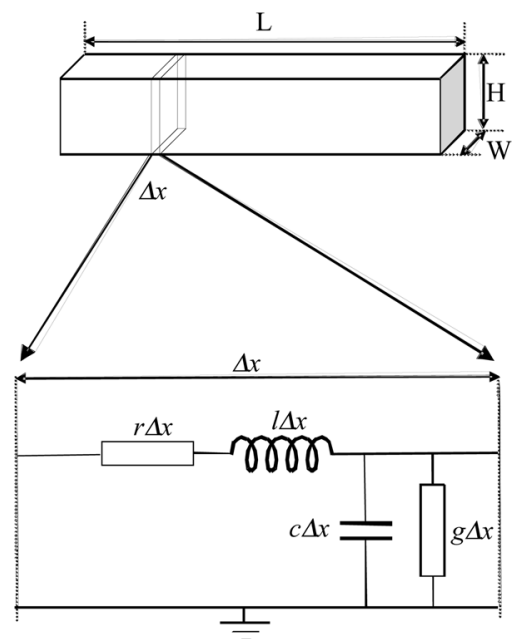

Fig. 2. Modeling of a defect-free wire of length (L), width (W), and height $(\mathrm{H})$ as a transmission line with $(\mathrm{L} / \Delta \mathrm{x})$ stages over a substrate connected to ground.

length $(\Delta \mathrm{x})$ of the transmission line where the $r, l, c$, and $g$ parameters are resistance, inductance, capacitance, and transconducance per unit length, respectively [22]. The meander is divided into $\mathrm{L} / \Delta \mathrm{x}$ of such stages. Note that the two combs are assumed to be connected to ground. Furthermore, according to typical real values, $g$ is found to be negligible and will not be considered in the characterization of the line.

Let us assume that an open defect is located at point $\mathrm{D}$ in the wire of length L. Fig. 3 illustrates the defective line considered as being made up of two separate transmission lines connected through the open. Since the rest of the line has no defects, their intrinsic electrical parameters are kept constant along both wires of length (D) and (L-D), respectively.

In general, since the defective circuit is not electrically symmetrical $(\mathrm{D} \neq \mathrm{L} / 2)$, its response to an external time-varying voltage excitation depends on the endpoint from which the external signal is being applied.

Fig. 4 illustrates the cases where the line is excited from both the near and far ends. Hereafter, the excitation connected as in the circuit shown at the top (bottom) of Fig. 4 will be denoted as $\mathrm{V}_{\mathrm{IR}}\left(\mathrm{V}_{\mathrm{IL}}\right)$, i.e., voltage input towards the right (left) direction. Fig. 5 shows the pair of transfer functions extracted according to the direction of the input signal connected to the line.

The use of the well-known expressions of the characteristic impedance $\left(\mathrm{Z}_{\mathrm{o}}=\sqrt{(r+s l) / s c}\right)$ and propagation constant $(\Gamma=\sqrt{(r+s l) s c})$ of a transmission-line stage [22], together with the inclusion of the open defect at the location $\mathrm{D}$, allows the response of the defective line to an input voltage excitation to be predicted. The two transfer functions of the complete line with an open defect $\left(\mathrm{R}_{\mathrm{op}}\right)$ located at a distance $\mathrm{D}$ from the left end are as follows:

$$
\begin{aligned}
\frac{V_{\mathrm{OR}}(s)}{V_{\mathrm{IR}}(s)} & =H_{R}(s) \\
& =\frac{1}{\cosh (L \Gamma)+\frac{R_{\mathrm{op}}}{2 Z_{o}} \sinh (L \Gamma) \cdot \sinh ((L-2 D) \Gamma)}
\end{aligned}
$$




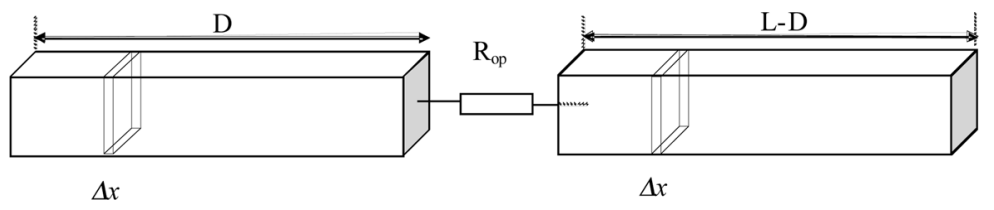

Fig. 3. Defective line (meander) of length $\mathrm{L}$ with an open defect in position $\mathrm{D}$ from the left end.

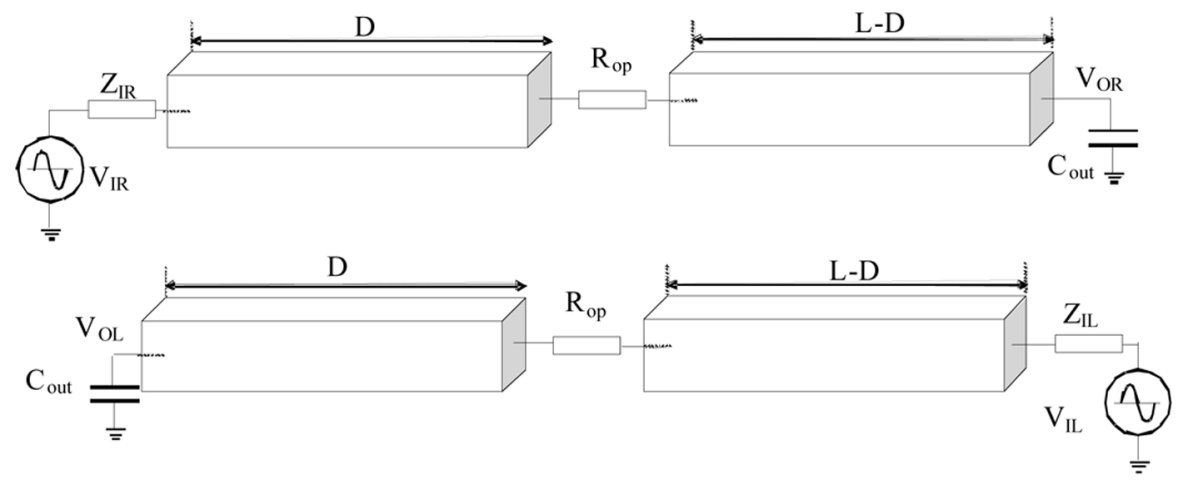

Fig. 4. In general, the response of the defective circuit to an external voltage depends on the end (extreme left or extreme right) from which the voltage signal is applied: $V_{\text {IR }}$ for input signals traveling to the right side of the figure or $\mathrm{V}_{\mathrm{IL}}$ for signals traveling to the left side.

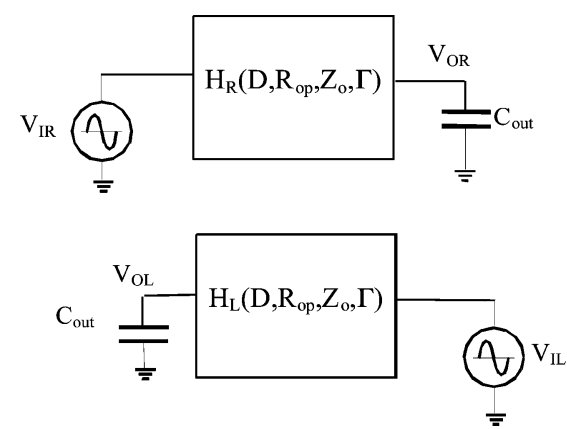

Fig. 5. The transfer function of the line depends on whether the external signal travels from left to right $\left(\mathrm{H}_{\mathrm{R}}\right)$ or vice versa $\left(\mathrm{H}_{\mathrm{L}}\right)$. The defect is modeled by parameters $D$ and $R_{o p}$. The characteristic impedance $\left(Z_{o}\right)$ and propagation constant $(\Gamma)$ of the line have also been taken into account. The transfer function of the fault-free line $\left(\mathrm{H}_{\mathrm{FF}}\right)$ is a particular case of $\mathrm{H}_{\mathrm{R}}$ and $\mathrm{H}_{\mathrm{L}}$ for $\mathrm{R}_{\mathrm{op}}=0$.

$$
\begin{aligned}
\frac{V_{\mathrm{OL}}(s)}{V_{\mathrm{IL}}(s)} & =H_{L}(s) \\
& =\frac{1}{\cosh (L \Gamma)-\frac{R_{\mathrm{op}}}{2 Z_{o}} \sinh (L \Gamma) \cdot \sinh ((L-2 D) \Gamma)}
\end{aligned}
$$

where $\left(\mathrm{V}_{\mathrm{IR}}(\mathrm{s}), \mathrm{V}_{\mathrm{OR}}(\mathrm{s})\right)$ and $\left(\mathrm{V}_{\mathrm{IL}}(\mathrm{s}), \mathrm{V}_{\mathrm{OL}}(\mathrm{s})\right)$ are the Laplace transforms of the input and output voltages for both cases illustrated in Fig. 4, and $\mathrm{R}_{\mathrm{op}}$ and $\mathrm{D}$ are the resistance and location parameters of the open defect.

In the previous expressions, the influence of the external circuitry (the internal output impedance of the external sources $Z_{I R}$ and $\mathrm{Z}_{\mathrm{IL}}$, and the output capacitance $\mathrm{C}_{\text {out }}$ created by the pad and the instrumentation used) has been considered to be negligible as compared with the line parameters. This issue will be discussed further in the section devoted to the experimental work.

\section{B. Defective Line Behavior}

This section is concerned with the use of (1) and (2) to extract the location $\mathrm{D}$ and the open resistance $\mathrm{R}_{\mathrm{op}}$. The unknowns $\mathrm{D}$ and $R_{\text {op }}$ cannot be isolated in a closed analytical expression because of their transcendent nature. Alternatively, graphical as well as numerical solutions can be used for the extraction of both parameters.

The expected transfer function versus input signal frequency is easily obtained from either (1) or (2), depending on the external side where the input signal is connected to the line. Fig. 6 gives an example of Bode diagram for a defective wire having an open located at $\mathrm{D}=0.3 \mathrm{~L}$. The resistance of the break $\mathrm{R}_{\mathrm{op}}$ has been taken equal to $20 \%$ of the total resistance of the defect-free wire (rL). Typical process parameter values of a 0.18 $\mu \mathrm{m}$ CMOS technology have been considered.

\section{Selection of the Excitation Frequency}

As shown in the previous Bode diagram, there is a range of frequencies increasing the sensitivity to the detection of the defective behavior.

The frequency-selection procedure consists in simulating the defect-free line and a defective one with a range of typical defects. Once both transfer functions $\left(\mathrm{H}_{\mathrm{L}}\right.$ and $\left.\mathrm{H}_{\mathrm{R}}\right)$ have been obtained, the two responses are analyzed, and the range of frequencies showing a sufficient difference to detect the open is selected. Fig. 7 illustrates the procedure for the particular case of Fig. 6. As can be observed, the range between 1 and $12 \mathrm{MHz}$ is the best option for testing purposes. The discontinuities in the bottom graph of Fig. 7 arise from the difference in the frequency at which the transfer functions $\mathrm{H}_{\mathrm{FF}}$ and $\mathrm{H}_{\mathrm{R}}$ change their phase (the graph shows the difference between their phases). 


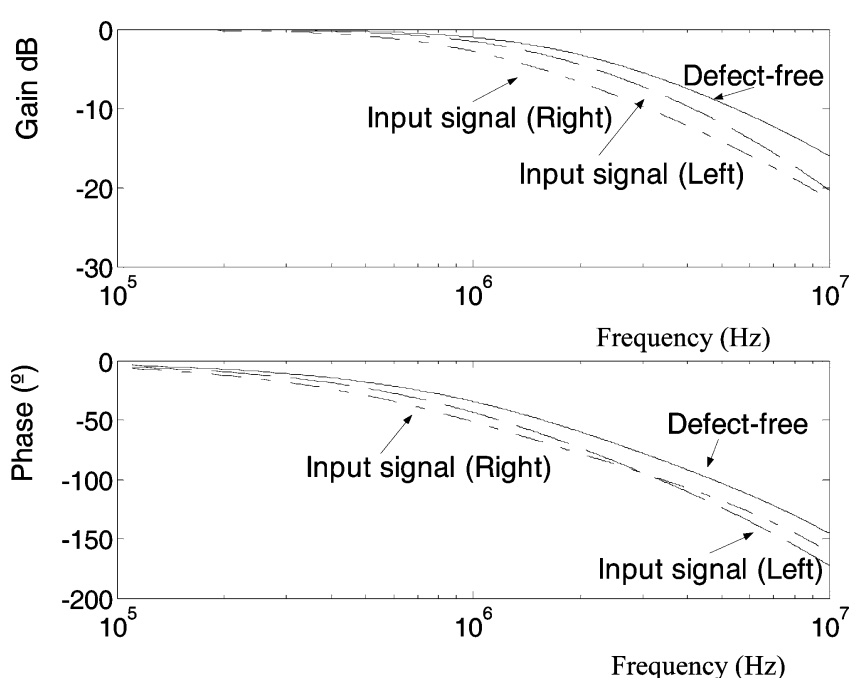

Fig. 6. Example of Bode diagrams of the defect-free and defective line with open location $\mathrm{D}=0.3 \mathrm{~L}$ and $\mathrm{R}_{\mathrm{op}}=0.2 \mathrm{rL}$ (where $\mathrm{r}$ is the resistance per unit length and $\mathrm{L}$ is the total length of the line, $\mathrm{L}=100 \mathrm{~mm}$, resulting in a total defect-free resistance of the line $\mathrm{rL}=437 \mathrm{k} \Omega$ ).
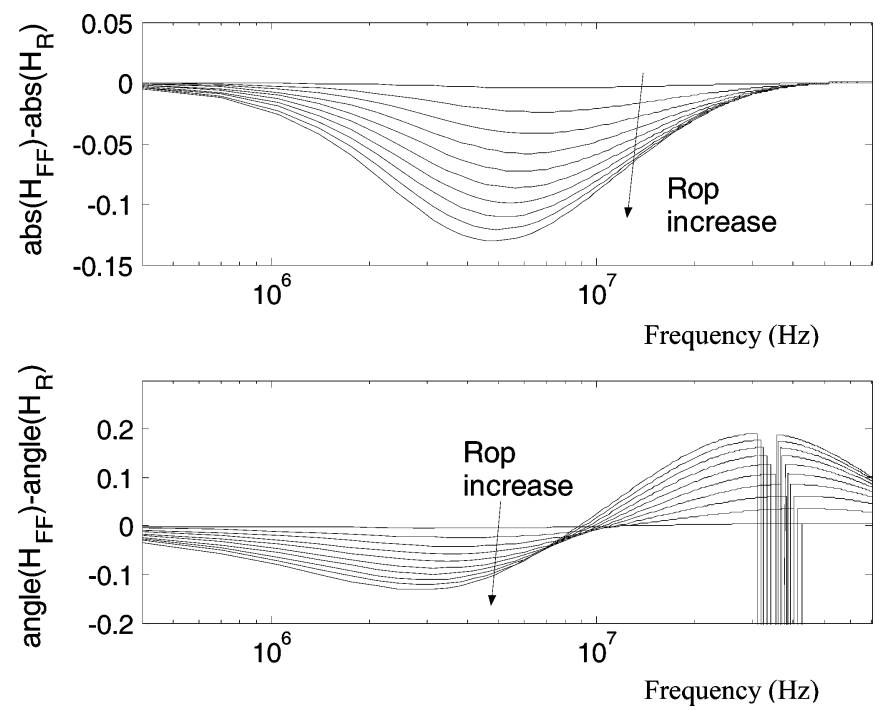

Fig. 7. Difference between the simulated fault-free transfer function of the line (illustrated in the previous figure) and a typical defective one. Different resistances of the open defect have been assumed ranging from $R_{o p}=0$ to $\mathrm{R}_{\mathrm{op}}=\mathrm{rL}$ in increments of $\Delta \mathrm{R}_{\mathrm{op}}=0.1 \mathrm{rL}$. (Top) Attenuation and (bottom) phase shift are shown.

\section{EXtRACTION OF THE OPEN PARAMETERS D AND $\mathrm{R}_{\text {op }}$}

The extraction of the location and resistance of the open in a defective line is presented in this section.

For a selected frequency previously computed from the characterization presented in Section II, left and right attenuations $\mathrm{G}_{\mathrm{R}}, \mathrm{G}_{\mathrm{L}}$ and phase shifts $\Phi_{\mathrm{R}}, \Phi_{\mathrm{L}}$ are measured. Note that the set of four measurements allows the set of four unknown parameters $\left(\mathrm{D}, \mathrm{R}_{\mathrm{op}}, \mathrm{Z}_{\mathrm{O}}, \Gamma\right)$ to be determined. The former pair of parameters informs about the open defect while the latter depends on the defect-free wire. With this technique, the uncertainty due to the lack of knowledge of the defect-free line $\left(Z_{O}, \Gamma\right)$ is eliminated since these parameters are initially considered as unknowns.

Different procedures may be used to solve the system of four equations and four unknowns. Considering the transcendent nature of the four expressions derived from (1) and (2), numerical or graph-based methods can be applied for solving them. In this way, a graph-based method can be employed where the intersection point $\left(\mathrm{D}, \mathrm{R}_{\mathrm{op}}, \mathrm{Z}_{\mathrm{O}}, \Gamma\right)$ of the four surfaces $\left(\mathrm{G}_{\mathrm{R}}, \mathrm{G}_{\mathrm{L}} \Phi_{\mathrm{R}}, \Phi_{\mathrm{L}}\right)$ provides the solution to the problem. However, it is well known that there exists a high correlation between the electrical parameters of neighboring defect-free test structures [10]. Under these circumstances, the pair of $\left(\mathrm{Z}_{\mathrm{O}}, \Gamma\right)$ parameters can be assumed to be known and the problem is simplified to finding the pair (D, $\left.R_{o p}\right)$. In such a case, the same graphical procedure can be followed but reduced to only two surfaces to be intersected. These two surfaces can be any two out of the four $\left(\mathrm{G}_{R}, \mathrm{G}_{\mathrm{L}} \Phi_{\mathrm{R}}, \Phi_{\mathrm{L}}\right)$.

The graphical method used in this paper proceeds as follows for the case of lack of information about the electrical parameters of the defect-free line. First, the attenuation $\left(\mathrm{G}_{\mathrm{R}}, \mathrm{G}_{\mathrm{L}}\right)$ and the phase shifts $\left(\Phi_{R}, \Phi_{L}\right)$ are measured at a chosen frequency. From (1) and (2), the set of (D, $R_{o p}$ ) pairs having the measured attenuations $\left(\mathrm{G}_{\mathrm{R}}, \mathrm{G}_{\mathrm{L}}\right)$ is obtained using any general-purpose solver software and is plotted on the $\left(D, R_{o p}\right)$ plain. The intersection between both curves occurs at point $\left(\mathrm{D}, \mathrm{R}_{\mathrm{op}}\right)_{\mathrm{AT}}$. The same procedure is followed for the phase shifts $\left(\Phi_{R}, \Phi_{L}\right)$, whose intersection occurs at point $\left(\mathrm{D}, \mathrm{R}_{\mathrm{Op}}\right)_{\mathrm{PH}}$. If the difference between the two points obtained is less than a precomputed value $\varepsilon(0.02 \%$ in this paper $)$, the procedure ends; otherwise, the same procedure is repeated for different pairs of $\left(Z_{0}, \Gamma\right)$ according to the information extracted from the process parameter variations. The procedure terminates when the difference between $\left(\mathrm{D}, \mathrm{R}_{\mathrm{op}}\right)_{\mathrm{AT}}$ and $\left(\mathrm{D}, \mathrm{R}_{\mathrm{Op}}\right)_{\mathrm{PH}}$ is smaller than $\varepsilon$.

Fig. 8 illustrates the result of applying the technique to a particular simulated case. In order to obtain the measured attenuations and phase shifts of a defective circuit, an HSPICE simulation has been carried out. The simulated $\left(D, R_{o p}\right)$ parameters have been circled, as shown in the figure. The intersection of the four curves (attenuation and phase shift for both input excitations) allows the defect location and resistance to be extracted. Note that although the example considers a small resistance $R_{o p}$ on the order of $20 \%$ of the defect-free line resistance, the value extraction is very accurate.

However, the unknown parameters of the nondefective line are expected to be similar to those of the testing structures of the rest of the wafer because of the high correlation between the electrical parameters already shown in previous works [10]. This allows an accurate prediction of the pair $\left(Z_{0}, \Gamma\right)$, and thus the system of two unknowns can be addressed with only two measurements. Since, in general, the measurement of gain values is more stable than that of delay values, the former pair of values is used $\left(\mathrm{G}_{\mathrm{R}}, \mathrm{G}_{\mathrm{L}}\right)$. Under this assumption, the procedure to extract the open parameters starts with the selection of the $\left(Z_{\mathrm{O}}, \Gamma\right)$ pair of values obtained from the characterization of the test structures surrounding the defective one. Next, a procedure similar to the one presented in the previous 


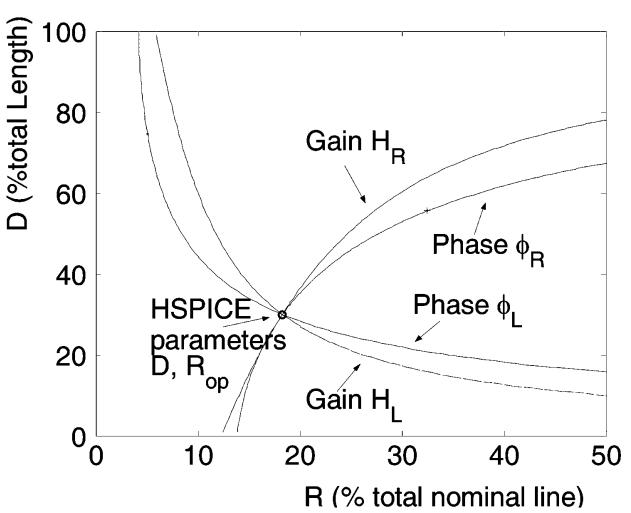

Fig. 8. Graphical solution for a particular defective line of length $\mathrm{L}=100$ $\mathrm{mm}, \mathrm{R}_{\mathrm{op}}=8 \mathrm{k} \Omega$, and $\mathrm{D}=0.3 \mathrm{~L}$.
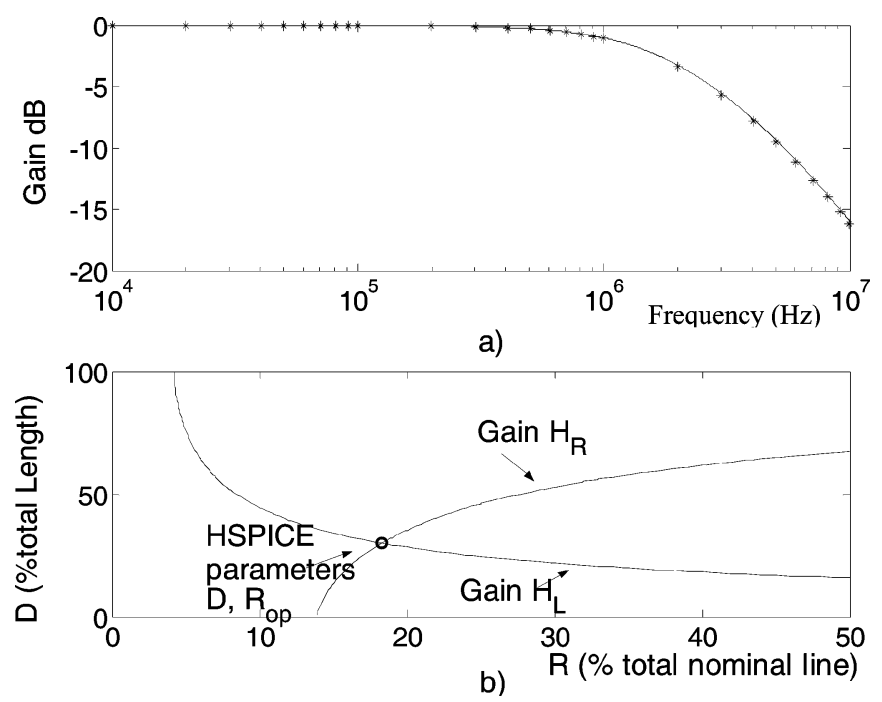

Fig. 9. Graphical solution for the same particular defective line of length $\mathrm{L}=$ $100 \mathrm{~mm}, \mathrm{R}_{\mathrm{op}}=8 \mathrm{k} \Omega$, and $\mathrm{D}=0.3 \mathrm{~L}$ presented in the previous figure. (a) The extraction of the defect-free electrical behavior by means of the neighboring test structures. (b) Graphical solution obtained from the gain measures.

paragraph is followed, but this time only the gain $\left(G_{R}, G_{L}\right)$ measurements are used, as illustrated in Fig. 9.

\section{A. Application Example}

The proposed method has been applied to a realistic 1-m-long monitor line, similar to that in [10]. After performing HSPICE simulations for a set of realistic open defects, the parameters $\left(\mathrm{D}, \mathrm{R}_{\mathrm{op}}\right)$ are calculated using the procedure based on measuring gains described above. Table I lists some of the results obtained. The two leftmost columns indicate the $\left(\mathrm{D}, \mathrm{R}_{\mathrm{op}}\right)$ used in the HSPICE simulation. The four (right) error columns indicate the percentage of error found in the calculated values referred to the correct (simulated) values or referred to the total length $(\mathrm{L})$ or line resistance $(\mathrm{r} \cdot \mathrm{L})$. Note that the prediction of the location of the open is very accurate, having errors lower than $1 \%$ of the total line length except in one case. The higher the defect resistance, the easier it is to calculate its location. The opposite
TABLE I

COMPARISON BETWEEN HSPICE SIMULATED $\left(D, R_{\mathrm{op}}\right)_{\text {HSP AND MATLAB }}$ Calculated $\left(\mathrm{D}, \mathrm{R}_{\mathrm{op}}\right)_{\mathrm{CAlC}}$ Parameters in a Realistic Aluminum MONITOR LINE OF L $=1 \mathrm{M}$ AND w $=0.32 \mu \mathrm{M}$. THE FREQUENCY TEST Was Selected AT $10 \mathrm{kHz}$. The DefeCt-Free Nominal LiNe Resistance Is $(\mathrm{r} \cdot \mathrm{L})=437 \mathrm{~K} \Omega$

\begin{tabular}{|l|l|l|l|l|l|}
\hline \multicolumn{2}{|c|}{ HSPICE } & \multicolumn{4}{c|}{$\left(\mathrm{D}, \mathrm{R}_{\text {op }}\right)_{\text {CALCULATED }}$ Error (\%) } \\
\hline \hline $\mathrm{D}_{\text {HSP }}$ & $\begin{array}{c}\mathrm{R}_{\text {opHSP }} \\
\Omega\end{array}$ & $\begin{array}{l}\mathrm{D}_{\text {CALC }} \\
\text { of } \\
\mathrm{D}_{\text {HSP }}\end{array}$ & $\begin{array}{l}\mathrm{D}_{\text {CALC }} \\
\% \text { of } \mathrm{L}\end{array}$ & $\begin{array}{l}\mathrm{R}_{\text {opCALC }} \\
\text { of } \\
\mathrm{R}_{\text {opHSP }}\end{array}$ & $\begin{array}{l}\mathrm{R}_{\text {opCALC }} \\
\% \text { of }(\mathrm{rL})\end{array}$ \\
\hline \hline $0.10 \mathrm{~L}$ & $8 \mathrm{k}$ & 11.7 & 1,17 & 3.58 & 0,07 \\
\hline & $20 \mathrm{k}$ & 8.60 & 0,86 & 4.24 & 0,19 \\
\hline & $40 \mathrm{k}$ & 1.50 & 0,15 & 4.81 & 0,44 \\
\hline & $100 \mathrm{k}$ & 0.70 & 0,07 & 5.00 & 1,14 \\
\hline & $200 \mathrm{k}$ & 0.01 & 0,00 & 5.08 & 2,32 \\
\hline $0.25 \mathrm{~L}$ & $8 \mathrm{k}$ & 3.12 & 0,78 & 1.31 & 0,02 \\
\hline & $20 \mathrm{k}$ & 1.20 & 0,30 & 0.39 & 0,02 \\
\hline & $40 \mathrm{k}$ & 0.32 & 0,08 & 0.07 & 0,01 \\
\hline & $100 \mathrm{k}$ & 0.15 & 0,04 & 0.17 & 0,04 \\
\hline & $200 \mathrm{k}$ & 0.04 & 0,01 & 0.24 & 0,11 \\
\hline & $8 \mathrm{k}$ & 1.51 & 0,68 & 8.62 & 0,16 \\
\hline & $12 \mathrm{k}$ & 1.02 & 0,46 & 3.85 & 0,11 \\
\hline & $20 \mathrm{k}$ & 0.84 & 0,38 & 2.52 & 0,12 \\
\hline & $40 \mathrm{k}$ & 0.29 & 0,13 & 6.94 & 0,64 \\
\hline & $100 \mathrm{k}$ & 0.02 & 0,01 & 5.25 & 1,20 \\
\hline & $200 \mathrm{k}$ & 0.01 & 0,00 & 5.06 & 2,32 \\
\hline
\end{tabular}

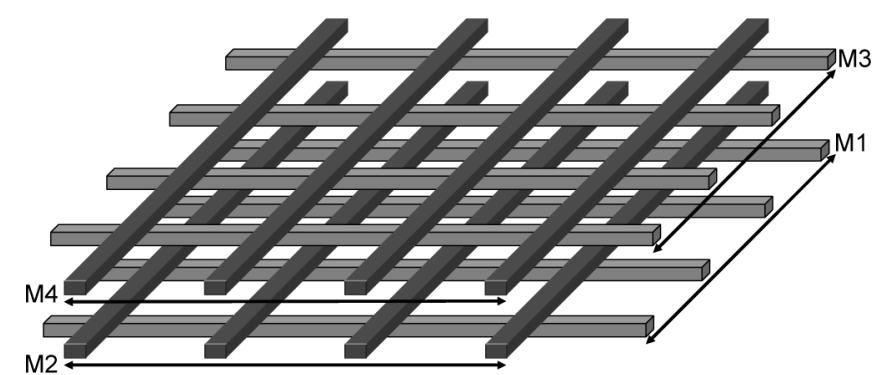

Fig. 10. In the measured YEMs, the metal lines of odd levels are orthogonally orientated to the metal lines of even levels.

behavior is found for $\mathrm{R}_{\mathrm{op}}$, for which errors lower than $2.5 \%$ of the total line resistance are found.

\section{EXPERIMENTAL RESULTS}

The methodology proposed for locating open defects has been applied to a set of aluminum yield enhancement monitors (YEMs) of a $0.18 \mu \mathrm{m} 6 \mathrm{M}$ Philips technology. Each of the monitors consists of six different comb-meander-comb structures, one per each metal level. The orientation of the lines depends on the metal level, being horizontal for odd metal levels and vertical for even levels, as shown in Fig. 10 (metals M5 and M6 are not illustrated for clarity.) The width of the lines is $\mathrm{W}=0.32 \mu \mathrm{m}$, and their spacing depends on the YEM structure, ranging from $\mathrm{S}=0.32$ to $2.0 \mu \mathrm{m}$. The test structure area of the monitors, which are almost square $(3.30 \times 3.00$ $\mathrm{mm}^{2}$ ), is close to $10 \mathrm{~mm}^{2}$.

As can be seen in Fig. 2, the measured meander is modeled to behave as a transmission line and is assumed to be coupled 


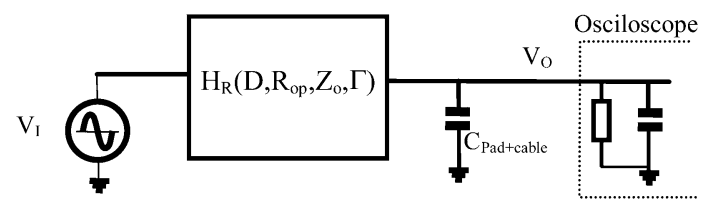

Fig. 11. Loading effect at the meander output due to the probe cable and the input circuitry of the oscilloscope.

to the electrically grounded plane. Each particular meander of the experimental set is surrounded by its (2) combs and the rest of the (5) meanders, which, in turn, have their respective combs $(5 \times 2)$.

To match the theoretical model with the real circuit, all the YEM combs and all the meanders, except the one being measured, are grounded by means of their corresponding pads. In this way, in the transmission-line model assumed in Fig. 2, the capacitance per unit length $c$ is found as the total parallel capacitance between the considered meander and the rest of the (5) meanders and (12) combs. During the measurements, 22 pads are grounded, and the input signal is connected at one of the meander pads while the response is observed at the other meander pad.

\section{A. Defect-Free Meander}

The first step in the experimental work consists in checking the degree of matching between the model proposed and the behavior of a fault-free meander. In order to obtain satisfactory results, the extraction of the transmission-line parameters must be accurate enough and the model must work for a sufficiently wide range of frequencies.

For the experimental measurements, different equipment can be used provided that its loading effect on the electrical results obtained is considered. Fig. 11 illustrates the schema of the loading effect caused by a passive $1 \times$ probe on the measured circuit. If a passive $10 \times$ probe is used, the inclusion of the division stage must also be considered. However, in the case of an active probe, the effect of the measuring instrument is, in practice, almost negligible. In this paper, the three different probes have been used and the expected results have been achieved.

Fig. 12 shows the experimental measurements (with lines) obtained for the gain and phase of two of the defect-free comb-meander-comb structures versus the modeled values (with points). Since the working frequencies are small enough, only the resistive and capacitive natures of the structure have been considered in $Z_{o}$ and $\Gamma$. Fitting between the experimental and calculated values for a range of frequencies has been used to select the parameters $r$ and $c$. The agreement between the predicted and the measured values is very good. Since one of the comb-meander-comb structures (MECB4) has a larger spacing between the meander and the combs, its capacitive coupling effect is smaller than for the other structure (MECB3), thus giving a smaller coupling fitting parameter $c$, as indicated in the figure. Moreover, as the coupling effect is less important, the relative impact of the rest of nonconsidered higher order
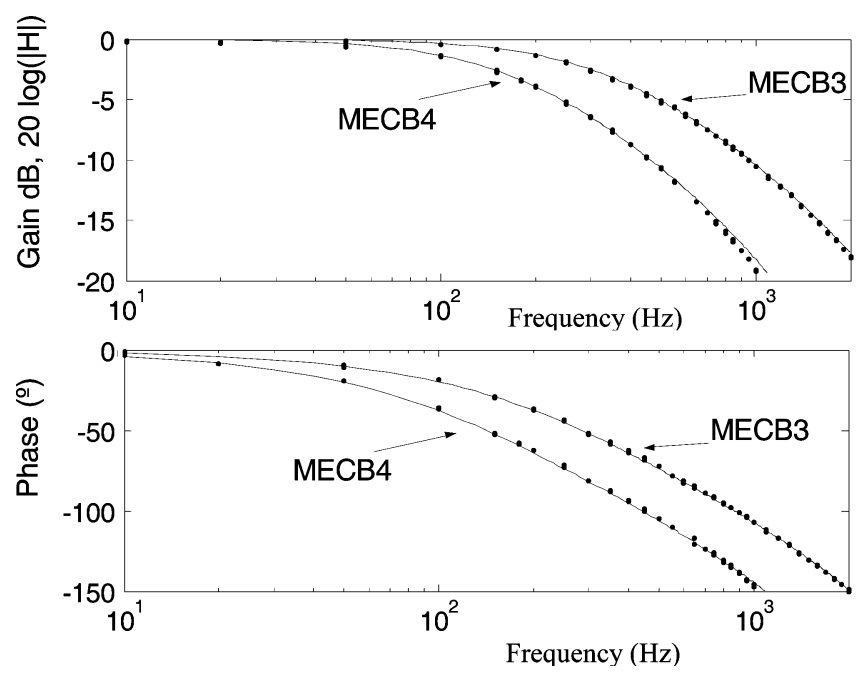

Fig. 12. Measured (lines) and modeled (points) gain and phase functions versus frequency for two of the defect-free comb-meander-comb structures measured. The parameters of the transmission lines have been found to be $c=185 \mathrm{pF} / \mathrm{m}$ and $\mathrm{r}=229 \Omega / \mathrm{m}$ for $\mathrm{MECB} 3(\mathrm{~W}=0.32 \mu \mathrm{m}$ and $\mathrm{S}=0.32 \mu \mathrm{m})$ and $\mathrm{c}=135$ $\mathrm{fF} / \mathrm{m}$ for MECB4 $(\mathrm{W}=0.32 \mu \mathrm{m}$ and $\mathrm{S}=0.48 \mu \mathrm{m}$ ) by fitting between the experimental and the predicted values.

coupling effects increases. This causes the model to start differing from the experimental results in the range of frequencies around kilohertz.

In the next section, experimental versus predicted gain and phase figures are presented for faulty meanders affected by resistive open defects.

\section{B. Defective Meanders}

In the case of a defective meander, both the $Z_{o}$ and $\Gamma(r$ and $c$ ) parameters and the open defect parameters $\mathrm{R}_{\mathrm{op}}$ and $\mathrm{D}$ must be extracted. There are four unknowns that must be derived from four measurements (gain and phase obtained from both sides of the meander). However, as proposed in the previous section, the knowledge obtained from the characterization of the defect-free meanders can be used to avoid measuring the phase response of the meander. For standard characterization equipment, measuring the phase response is less accurate than measuring the gain response. Indeed, the well-known good correlation between the location of such YEM structures and their dc electrical response allows the $r$ value to be easily derived provided the information about their location on the wafer is used. Since this good correlation is mainly due to photolithography (geometrical) issues, the $c$ value is also easily derived because of its dependence on the spacing between the metal lines and on their thickness. Starting from the knowledge of $r$ and $c$, only the parameters of the open defect need to be obtained and only two measurements must be performed, i.e., the gain response from both sides of the defective meander $\mathrm{G}_{R}$ and $\mathrm{G}_{\mathrm{L}}$.

Fig. 13 illustrates the results obtained from the application of the methodology to find the location and resistance of an open defect. The electrical gains predicted from the two ends of the meander are shown in a three-dimensional (3-D) graph versus the (unknown) location and resistance of the open at a particular frequency. The intersection of such 3-D graphs with 


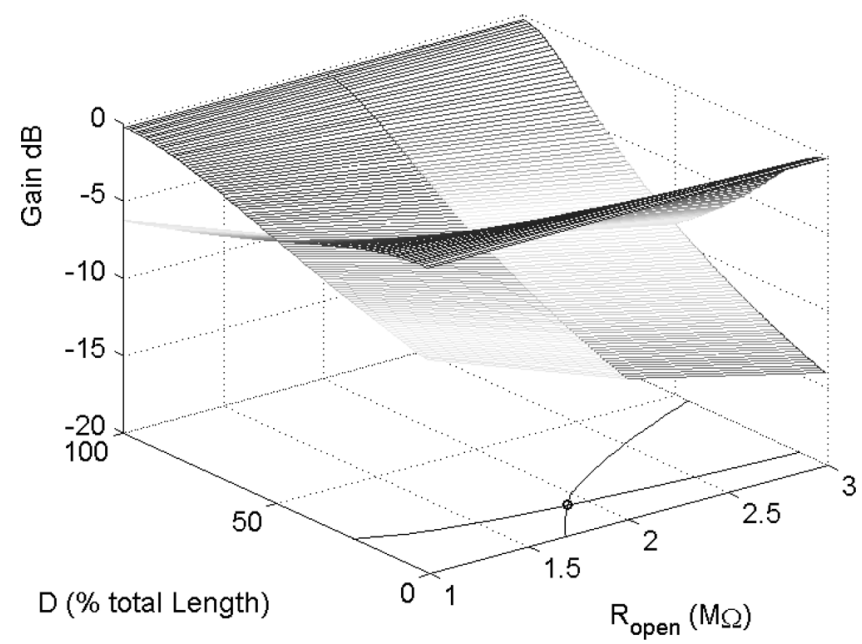

Fig. 13. Electrical gains (from the left and right ends of the meander) predicted for a defective structure versus the unknown location and resistance of the open defect at a particular frequency value. The measured gains from left and right ends are shown as the two level curves intersecting at the location and resistance obtained: $\mathrm{D}=14.1 \%$ of the total meander length and $\mathrm{R}_{\mathrm{op}}=1.9 \mathrm{M} \Omega$.

the two measured gain values $\left(\mathrm{G}_{\mathrm{R}}\right.$ and $\left.\mathrm{G}_{\mathrm{L}}\right)$ determines the two level curves also shown in the figure. The intersection between these two curve levels provides the location and resistive value of the open defect, causing the defective behavior in this case $\left(\mathrm{D}=14.1 \%\right.$ of the total meander length and $\mathrm{R}_{\mathrm{op}}=1.9 \mathrm{M} \Omega$ ).

Once the open defect has been characterized, the inverse process is performed to check the precision of the result, i.e., the measured and predicted gains at different frequencies are depicted, as shown in Fig. 14. Good agreement is observed between them for a wide range of frequencies going up to several kilohertz. The phase values are also illustrated, although the data related to the phase have not been used for deriving the pair (D, $\left.\mathrm{R}_{\mathrm{op}}\right)$.

In the next section, a visual inspection of some of the measured defects is presented to check the accuracy of the predicted locations.

\section{OBIRCH Inspection}

The optical beam induced resistance change (OBIRCH) method is an indispensable failure analysis tool in the semiconductor industry. It is useful not only for test structures but also for final products. The basic principle of OBIRCH is very simple [19], [20]. The first step consists in radiating the surface to be inspected with a laser beam. This radiation heats the surface, which, as a result, changes its electrical resistance. The change in resistance causes a variation in the current flowing through the structure. This current variation can be displayed on a cathode-ray tube in the form of brightness change. Fig. 15 illustrates the setup required to apply this technique to the measured comb-meander-comb structures.

Fig. 16 shows the gain values measured and predicted as presented in the previous sections for a meander that has been visually inspected by the OBIRCH method. The prediction has been $\mathrm{D}=40.0 \% \pm 0.5 \%$ of the total meander length for an open defect having $R_{\mathrm{op}}=22 \mathrm{M} \Omega$. The use of the measurements at
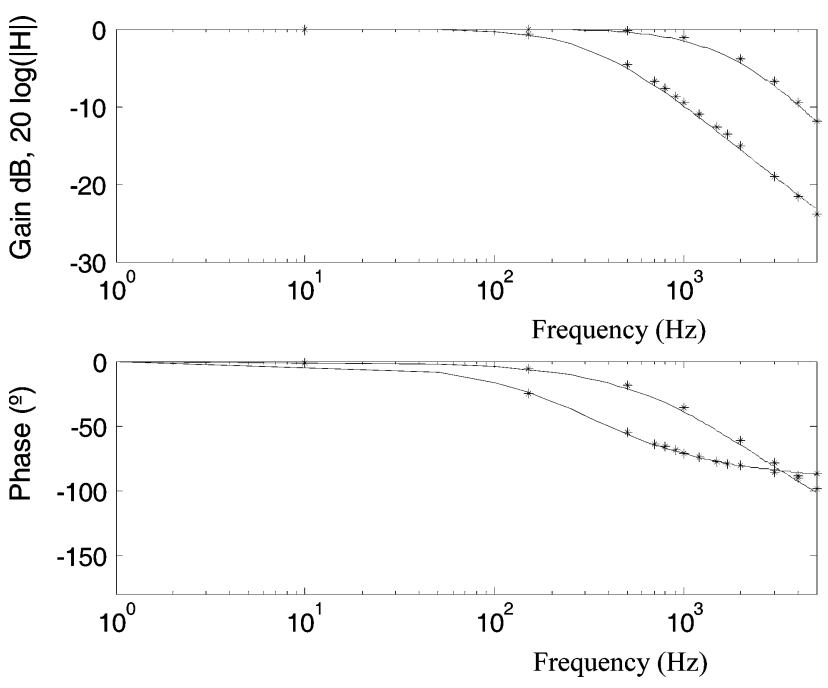

Fig. 14. Comparison between the measured gain and phase and their predicted values at different frequencies for the defective meander presented in the previous figure. The measured values are marked with asterisks while the predicted values are drawn with lines. The defect location and the resistance obtained from the previous figure have been used.

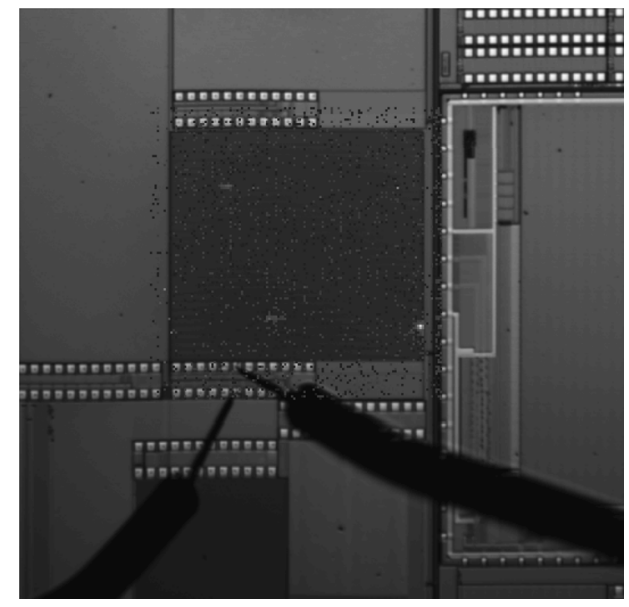

Fig. 15. Comb-meander-comb structure being excited for OBIRCH inspection. The two needles connected to the Meander Left pad and the Meander Right pad for the M3 level are shown.

different frequencies gives rise to different predictions, which results in an uncertainty. A simple arithmetic mean value has been used for generating this uncertainty. The applied visual OBIRCH inspection (see Fig. 17) shows the good agreement between the predicted location and the real position of the open defect.

Fig. 18 shows the location of another open defect calculated by the proposed methodology. Fig. 19 illustrates the result of the visual inspection for this defect predicted to be located at $\mathrm{D}=97 \% \pm 1 \%$ with $\mathrm{R}_{\mathrm{op}}=150 \mathrm{k} \Omega$. The higher uncertainty is due to the low value of the defect resistance since its impact on the meander behavior is smaller. Good agreement between experimental and predicted locations is also obtained.

The methodology proposed for locating open defects in YEM structures starts with the assumption that only one open defect at a time is present in a meander. Because of the density of random 

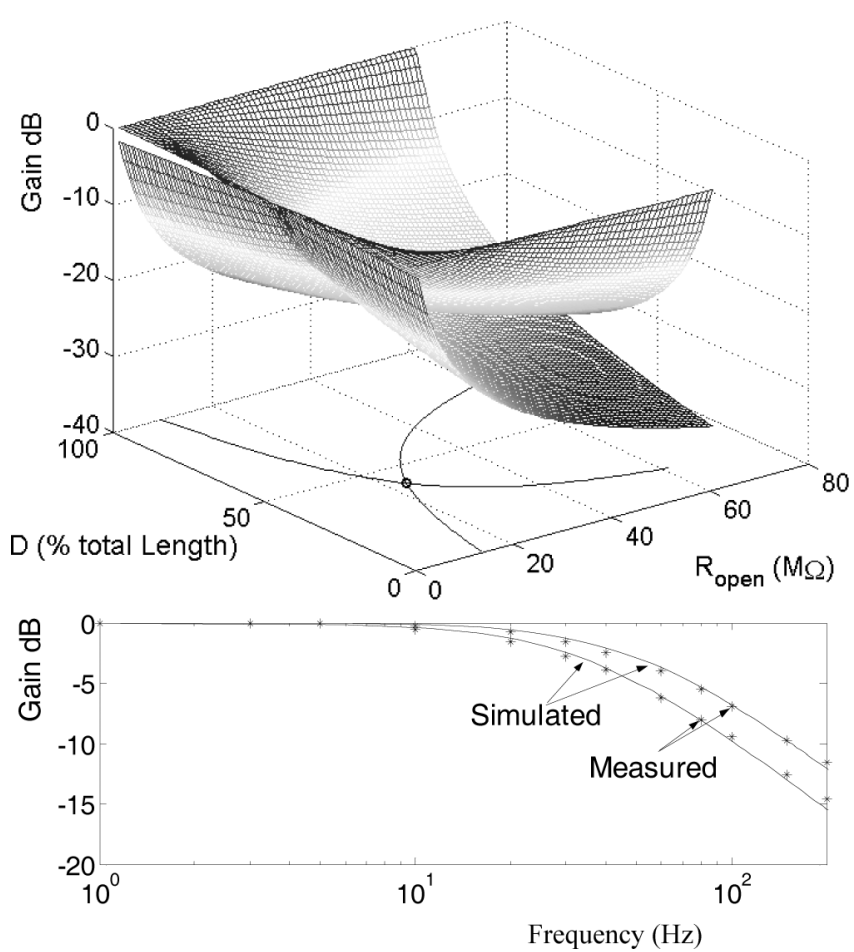

Fig. 16. Gain measurements versus predicted values at different frequencies for a defective meander with an $R_{\mathrm{op}}=22 \mathrm{M} \Omega$ and a predicted location $\mathrm{D}=$ $40.5 \% \pm 0.5 \%$ of the total meander length referred to the top part of the picture.

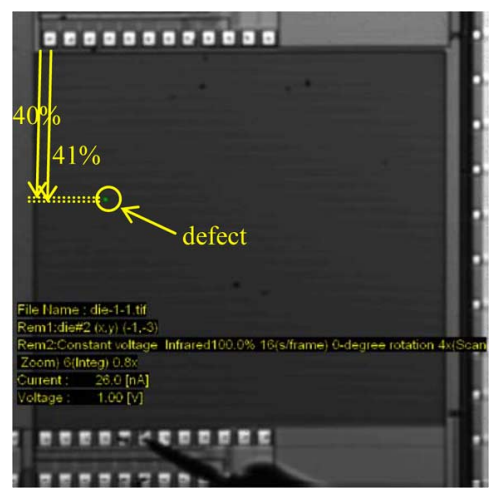

Fig. 17. Location obtained by visual OBIRCH inspection for the defective meander illustrated in the previous figure. The location was predicted between $40 \%$ and $41 \%$ of the top of the meander. The real location of the open defect agrees with the prediction.

defects in current semiconductor technologies, the probability of having more than one defect is quite low. In fact, the area devoted to such kind of YEM structures is big enough to have one defect. However, the open defect location methodology has also been applied to structures with more than one resistive open defect. Fig. 20 shows the result of the OBIRCH inspection on a meander with two open defects. Since the model assumed only one open defect to cause the faulty behavior, the predicted values were farther from the end than reality. Although this result is consistent with the method proposed, it is incorrect. Only one open is assumed to predict the correct location of the defect, which is actually the most likely case in mature processes. Fig. 21 shows the gain values measured and predicted for the
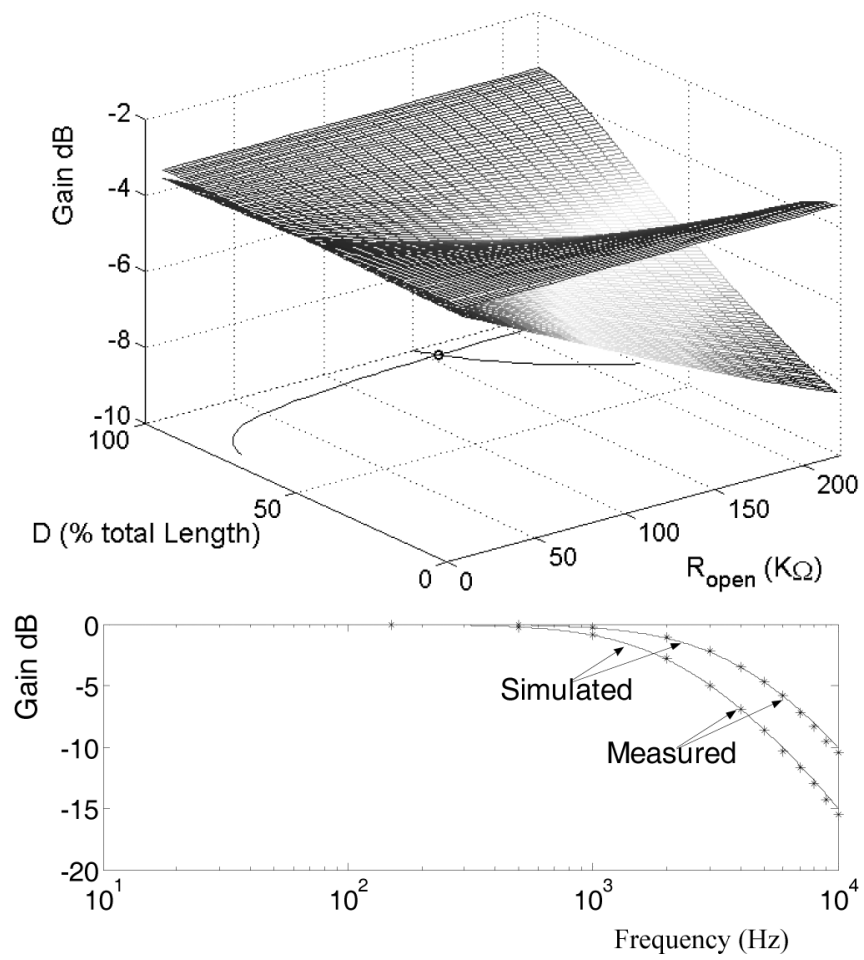

Fig. 18. Gain measurements versus predicted values at different frequencies for a defective meander with a $R_{o p}=150 \mathrm{k} \Omega$ and a predicted location $\mathrm{D}=$ $97 \% \pm 1 \%$ of the total meander length referred to the top part of the picture.

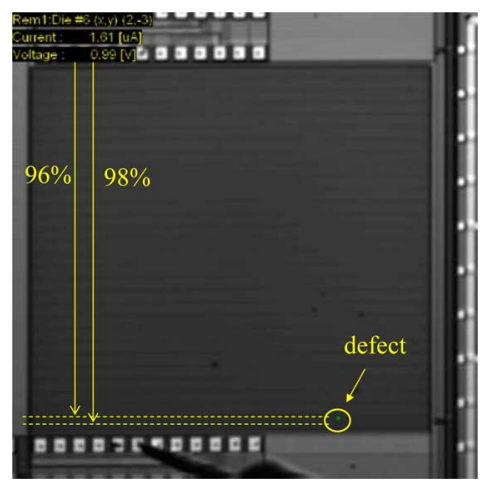

Fig. 19. Location obtained by visual OBIRCH inspection for the defective meander illustrated in the previous figure. The location was predicted between $96 \%$ and $98 \%$ of the top of the meander. The real location of the open defect agrees with the prediction.

defective circuit with two open defects illustrated in Fig. 20. As expected, the presence of two defects causes a certain level of discrepancy between the measured and predicted gain values compared to the previous single-defective examples shown in Figs. 16 and Fig. 18.

\section{SCAlability OF THE MEthod}

In order to evaluate the scalability of the proposed method to YEM structures manufactured in different nanometric technologies, some (typical) electrical and physical parameters have been considered. The range of optimum frequencies for each technology node has been calculated, as will be shown next, for a standard meander-comb YEM with an area of $1 \mathrm{~mm}^{2}$. In addition, the range of detected resistances has been characterized. 


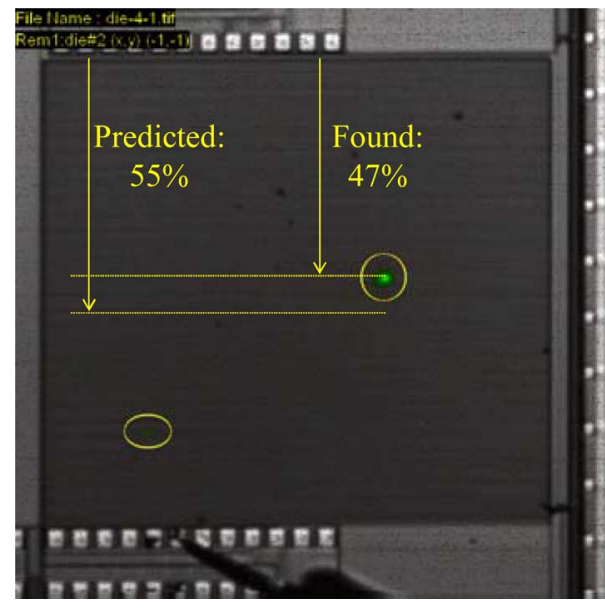

Fig. 20. Location obtained with OBIRCH for a defective meander affected by two open defects. Since the model used only assumes one resistive open defect per defective meander, the predicted location was farther from the end than the actual location found. This result is consistent with the model considered. However, in current mature processes, the probability of having more than one open defect per meander is quite low.

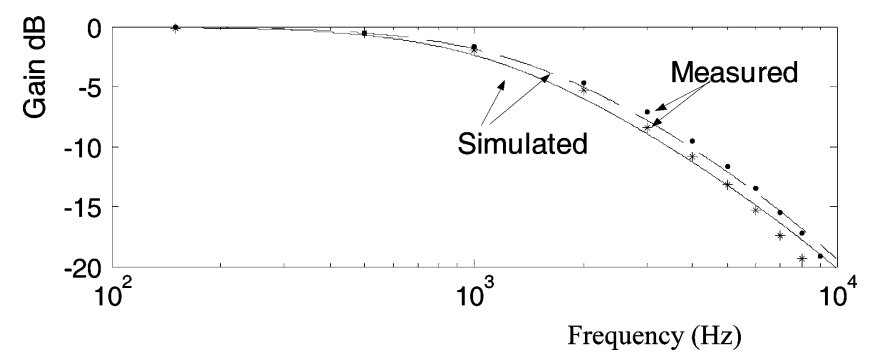

Fig. 21. Gain measurements versus predicted values at different frequencies for the defective meander with a total $R_{\mathrm{op}}=650 \mathrm{k} \Omega$ and a predicted location $\mathrm{D}=55 \% \pm 1 \%$ of the total meander length referred to the top part of the picture.

TABLE II

PHYSICAL AND EleCtrical PARAMETERS OF THE INTERMEDIATE WIRING OF NANOMETRIC TECHNOLOGIES [23]

\begin{tabular}{|c||c|c|c|c|c|}
\hline $\begin{array}{c}\text { ITRS } \\
\text { node } \\
(\mathrm{nm})\end{array}$ & $\begin{array}{c}\text { wiring } \\
\text { pitch } \\
(\mathrm{nm})\end{array}$ & $\begin{array}{c}\mathrm{AR} \\
\text { aspect } \\
\text { ratio }\end{array}$ & $\begin{array}{c}\text { dielectric } \\
\mathrm{k}\end{array}$ & $\begin{array}{c}\mathrm{r} \\
(\mathrm{k} \Omega / \mathrm{m})\end{array}$ & $\begin{array}{c}\mathrm{c} \\
(\mathrm{pF} / \mathrm{m})\end{array}$ \\
\hline \hline $\mathbf{1 3 0}$ & 350 & 1.5 & $3.0-3.6$ & 292 & 210 \\
\hline $\mathbf{9 0}$ & 210 & 1.7 & $3.1-3.4$ & 716 & 195 \\
\hline $\mathbf{6 5}$ & 150 & 1.7 & $2.7-3.0$ & 1404 & 175 \\
\hline $\mathbf{4 5}$ & 110 & 1.8 & $2.5-2.8$ & 2558 & 160 \\
\hline
\end{tabular}

Table II shows the main parameters that determine the electrical properties of the meander-comb structure for several technologies assuming copper $(\mathrm{Cu})$ as the manufacturing material ( $\rho=2.2 \mu \Omega-\mathrm{cm}$ ). In our analysis, the width and spacing of the lines have been assumed to be minimum and equal to half of the wiring pitch. The aspect ratio AR is also needed to determine the meander resistance per unit length ( $\mathrm{r}$, shown in $\mathrm{k} \Omega / \mathrm{m}$ ) and the capacitance per unit length (c, in $\mathrm{pF} / \mathrm{m})$.

Assuming a YEM with an area of $1 \mathrm{~mm}^{2}$, the total meander resistance $\left(R_{M}\right)$ is shown in Table III. For the considered technologies, the meander length (not shown) ranges from nearly $1 \mathrm{~m}$ for the $130 \mathrm{~nm}$ node to almost $4 \mathrm{~m}$ for the $45 \mathrm{~nm}$ node.
TABLE III

Total Meander Resistance $\left(\mathrm{R}_{\mathrm{M}}\right)$ For DifFerent Technology Nodes $\left(\right.$ YEM Area $\left.=1 \mathrm{MM}^{2}\right)$ AND OPTIMUM RANGE OF MEASURING FREQUENCIES Versus Resistance of THE OPEN DEFeCt Rop (REFERRED to $\mathrm{R}_{\mathrm{M}}$ )

\begin{tabular}{|c||c|c|c|c|}
\hline $\begin{array}{c}\text { ITRS } \\
\text { node } \\
(\mathrm{nm})\end{array}$ & $\begin{array}{c}\mathrm{R}_{\mathrm{M}} \\
(\mathrm{M} \Omega)\end{array}$ & $\begin{array}{c}\mathrm{f}(\mathrm{kHz}) \\
\left(\mathrm{Rop}=0.1 \mathrm{R}_{\mathrm{M}}\right)\end{array}$ & $\begin{array}{c}\mathrm{f}(\mathrm{kHz}) \\
\left(\mathrm{Rop}=1 \mathrm{R}_{\mathrm{M}}\right)\end{array}$ & $\begin{array}{c}\mathrm{f}(\mathrm{kHz}) \\
\left(\mathrm{Rop}=10 \mathrm{R}_{\mathrm{M}}\right)\end{array}$ \\
\hline \hline $\mathbf{1 3 0}$ & 0.326 & $10-35$ & $6-14$ & $2-3$ \\
\hline $\mathbf{9 0}$ & 1.332 & $1.5-4.5$ & $1.0-2.2$ & $0.3-0.4$ \\
\hline $\mathbf{6 5}$ & 3.656 & $0.5-1.4$ & $0.30-0.65$ & $0.09-0.12$ \\
\hline 45 & 9.252 & $0.15-0.45$ & $0.10-0.20$ & $0.02-0.04$ \\
\hline
\end{tabular}

TABLE IV

RANGe of Resistance of the OPEn Defects Detected at a MEAsuring FREQUENCY OF $50 \mathrm{~Hz}$ IN A YEM OF $1 \mathrm{MM}^{2}$

\begin{tabular}{|c||c|c|}
\hline $\begin{array}{c}\text { ITRS node } \\
(\mathrm{nm})\end{array}$ & $\begin{array}{c}\text { minimum } \\
\operatorname{Rop}(\mathrm{k} \Omega)\end{array}$ & $\begin{array}{c}\text { maximum } \\
\operatorname{Rop}(\mathrm{M} \Omega)\end{array}$ \\
\hline \hline $\mathbf{1 3 0}$ & 10 & 130 \\
\hline $\mathbf{9 0}$ & 100 & 80 \\
\hline $\mathbf{6 5}$ & 310 & 66 \\
\hline $\mathbf{4 5}$ & 790 & 51 \\
\hline
\end{tabular}

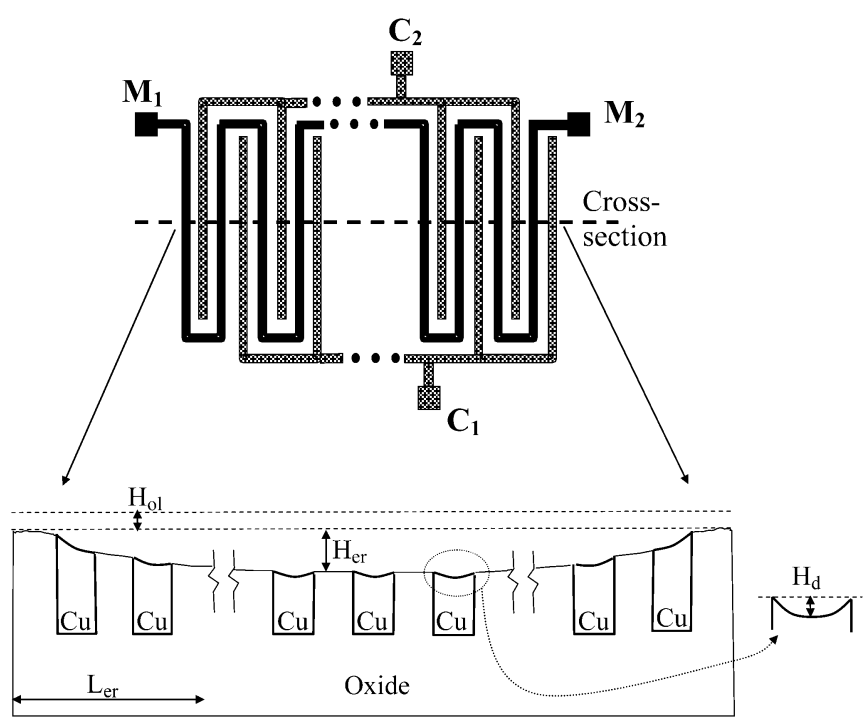

Fig. 22. Cross-sectional view of metal dishing and erosion effects after CMP process in a fine line and fine space interconnect structure [29]. $\mathrm{H}_{\mathrm{er}}$ refers to the thickness loss at each particular interconnect line while $\mathrm{H}_{\mathrm{ol}}$ refers to a global field oxide loss over the whole structure. The metal nonplanarity due to dishing is modeled by $\mathrm{H}_{\mathrm{d}}[26]$.

The three rightmost columns of Table III show the optimum range of frequencies for the proposed method versus three values of the resistance of the open Rop (referred to the total meander resistance $R_{M}$ ). The value of the optimum working frequency has been extracted from the analysis of the behavior shown in Fig. 7 and assuming an active probe for the measurements. Note that the optimum value of the measuring frequency depends on the location of the open defect in the meander, and, for that reason, the optimum frequency is presented as a range. The highest frequencies of the range are the optimum for open defects located near the end points of the meander.

From Table III, it is clear that the range of frequencies capable of locating a resistive open defect narrows with shrinking the technology. As an illustrative example taken from the table, 


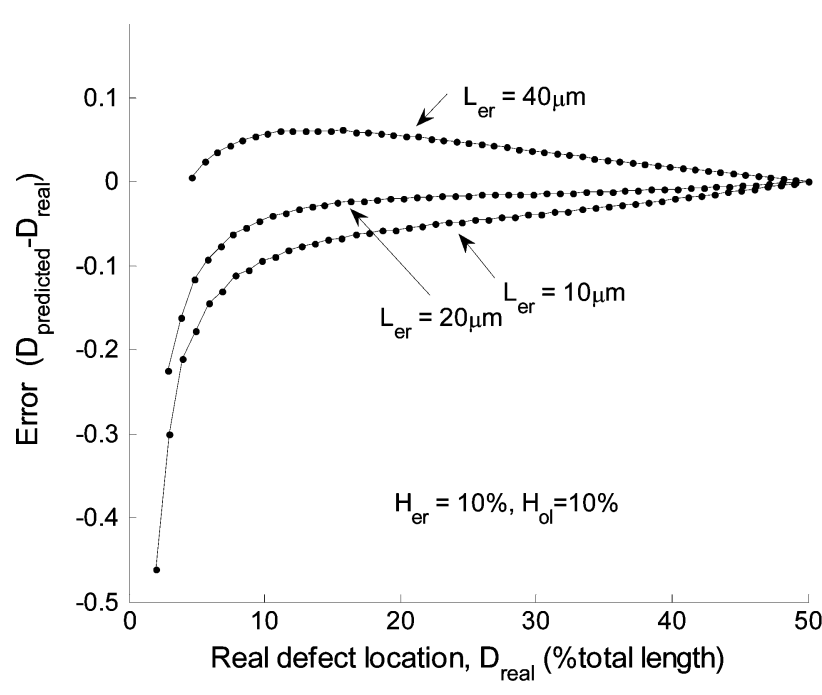

a)

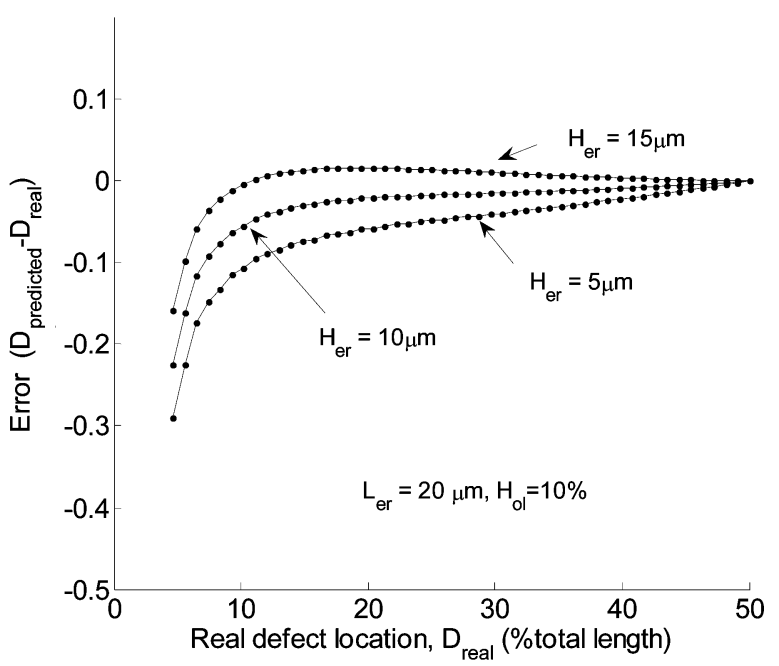

b)

Fig. 23. Error in the prediction of the location of an open defect with $R_{\mathrm{op}}=\mathrm{R}_{\mathrm{M}}$ in a $45 \mathrm{~nm}$ technology under the effect of dishing and erosion after CMP process (see Fig. 22). (a) YEM with a global field oxide loss of the $10 \%$ of the nominal value, $10 \%$ difference between the edge and stable mean resistance, and different distances $\left(\mathrm{L}_{e r}\right)$ between edge and stable resistance lines. (b) YEM with different $\left(\mathrm{H}_{\mathrm{er}}\right)$ mean resistance between the edge lines and the middle lines while $\mathrm{L}_{\mathrm{er}}$ and $\mathrm{H}_{\mathrm{ol}}$ are kept constant.

a resistive open defect of around $R_{o p}=3.26 \mathrm{M} \Omega$ is well predicted by a range of $\mathrm{f}=2-3 \mathrm{kHz}$ in a $130 \mathrm{~nm}$ technology, but a similar open defect of $\mathrm{R}_{\mathrm{op}}=3.66 \mathrm{M} \Omega$ has an optimum range of $\mathrm{f}=0.3-0.65 \mathrm{kHz}$ in a $65 \mathrm{~nm}$ technology.

Furthermore, the range of resistances detected by the proposed method has been analyzed for the previous technology nodes. In order to characterize the maximum detectable resistive open defect, a $100 \mathrm{mV}$ magnitude has been assumed as the minimum signal measurable at the meander output (given an input magnitude of $10 \mathrm{~V}$ ). Symmetrically, the minimum resistive open defect has been considered as that capable of causing a deviation from the defect-free response of the circuit of, at least, $100 \mathrm{mV}$. The results are presented in Table IV for a YEM with an area of $1 \mathrm{~mm}^{2}$. As the technology feature shrinks, the range of detected resistive opens narrows too.

Another issue to be taken into account when applying the proposed technique is the impact of dishing and erosion caused by chemical mechanical polishing (CMP) in damascene $\mathrm{Cu}$ lines [24], [25], [30], since sheet resistance is a function of line width and pattern density. Efficient modeling is available for mature processes [26]-[28], and the metal thickness can be controlled provided the comb-meander structure has uniform density. However, special attention must be paid to the edge of the comb-meander structure because of the possible change in density.

The effect of the nonuniform electrical characteristics of a $\mathrm{Cu}$ meander due to dishing and erosion has been analyzed according to the cross-sectional profile illustrated in Fig. 22. As far as the erosion effect is concerned, the median resistance of each line is a function of position on the array. The resistance is assumed to be lower at the structure edge but to increase rapidly proceeding inwards. After a few tens of $\mu \mathrm{m}$ from the array edge $\left(\mathrm{L}_{\mathrm{er}}\right)$, the mean resistance of each line can be considered stabi- lized to the value derived from erosion $\mathrm{H}_{\mathrm{er}}$ [25]. A global field oxide loss $\left(\mathrm{H}_{\mathrm{ol}}\right)$ is also included in the meander structure. In relationship with the dishing effect, it is expected to have a small impact on such narrow lines [29], [26]; however, its effect has also been included and modeled by $\mathrm{H}_{\mathrm{d}}$ (see Fig. 22) according to the dishing radius concept [26], [27].

In order to illustrate the impact of dishing and erosion on the proposed methodology, an open defect with resistance $R_{o p}=$ $\mathrm{R}_{\mathrm{M}}$ has been included in a $1 \mathrm{~mm}^{2}$ YEM for the nanometer technologies considered in Table II. Each line of the comb-meander structure has been modeled through its $\mathrm{ABCD}$ matrix with the inclusion of the $\mathrm{Cu}$ thickness variations shown in Fig. 22. The electrical response of the whole meander has been characterized by computing the global ABCD matrix. Fig. 23(a) shows the error in the prediction of the defect location for an illustrative case in a $45 \mathrm{~nm}$ technology with a global field oxide loss of $10 \%$ of the nominal oxide thickness $\left(\mathrm{H}_{\mathrm{Ol}}=10 \%\right)$, a decrement in the $\mathrm{Cu}$ thickness $\left(\mathrm{H}_{\mathrm{er}}\right)$ at the middle of the structure of $10 \%$ related to the edge thickness value, and three different edge distances to the stable mean resistance zone $\left(\mathrm{L}_{\mathrm{er}}=10 \mu \mathrm{m}, \mathrm{L}_{\mathrm{er}}=20 \mu \mathrm{m}\right.$, and $\left.\mathrm{L}_{\mathrm{er}}=40 \mu \mathrm{m}\right)$. The proposed working frequency $\mathrm{f}=200$ $\mathrm{Hz}$ presented in Table III has been used for the location of the defect. Fig. 23(b) shows the error in the prediction of the defect location for the same structure with $\mathrm{H}_{\mathrm{ol}}=10 \%$ and $\mathrm{L}_{\mathrm{er}}=20 \%$ and three different edge distances $\mathrm{L}_{\mathrm{er}}=5,10$, and $15 \mu \mathrm{m}$. Due to the symmetry of the electrical behavior, only locations between 0 and $50 \%$ of the total length of the YEM are shown. The impact of dishing has not been shown in Fig. 23 due to its small effect on narrow lines.

The low impact of dishing and erosion shown in Fig. 23 illustrates the robustness of the proposed method for the location of resistive open defects except for locations close to the edges of meander structures. 


\section{CONCLUSION}

An experimental method to electrically characterize weak opens and at the same time identify the location of such defects has been proposed. It uses passive meander process monitor structures accessible at both ends. The attenuation and phase shift (delay) for time-varying signals at both ends provide the four measures from which the defect parameters $R_{\mathrm{op}}$ and its location D are extracted. Only one open defect is assumed to affect each defective meander. The inherent redundancy of the measures enables the adequate characterization in the presence of unknown shifts in the line parameters.

This paper also shows the reduction of the measurements needed to determine the location of open defects with the knowledge obtained from the defect-free meander structures surrounding the defective one. In this way, only the attenuation (gain) figures must be measured to predict the location of open defects.

Real defective meanders have been analyzed and the location of their open defects has been predicted. Visual inspection by OBIRCH techniques shows the agreement between the theoretical location of the defect and the actual location.

\section{ACKNOWLEDGMENT}

The authors thank C. Hora, B. Kruseman, and M. Lousberg for their enriching comments.

\section{REFERENCES}

[1] W. Maly, P. K. Nag, and P. Nigh, "Testing oriented analysis of CMOS ICs with opens," in Proc. Int. Conf. Computer-Aided Design, 1988, pp. 344-347.

[2] C. L. Henderson, J. M. Soden, and C. F. Hawkins, "The behaviour and testing implications of CMOS IC logic gate open circuits," in Proc. Int. Test Conf., 1991, pp. 302-303.

[3] J. C. M. Li, C.-W. Tseng, and E. J. McCluskey, "Testing for resistive opens and stuck opens," in Proc. Int. Test Conf., 2001, pp. 1049-1058.

[4] S. Chakravarty and A. Jain, "Fault models for speed failures caused by bridges and opens," in Proc. VLSI Test Symp., 2002, pp. 373-378.

[5] M. Azimane and A. K. Majhi, "New test methodology for resistive open defect detection in memory address decoders," in Proc. VLSI Test Symp., 2004, pp. 123-128.

[6] W. Lukaszek, K. G. Grambow, and W. J. Yarbrough, "Test chip based approach to automated diagnosis of CMOS yield problems," IEEE Trans. Semicond. Manuf., vol. 3, pp. 18-27, Feb. 1990.

[7] D. K. de Vries and P. L. C. Simon, "Calibration of open interconnect yield models," in Proc. IEEE Int. Symp. Defect Fault Tolerance VLSI Syst., 2003, pp. 26-33.

[8] J. B. Khare, W. Maly, and M. E. Thomas, "Extraction of defect size distribution in an IC layer using test structure data," IEEE Trans. Semicond. Manuf., vol. 7, pp. 354-368, Aug. 1994.

[9] E. M. J. G. Bruls, F. Camerik, H. J. Kretschman, and J. A. G. Jess, "A generic method to develop a defect monitoring system for IC processes," in Proc. Int. Test Conf., 1991, pp. 218-227.

[10] R. Rodríguez-Montañés, P. Volf, and J. Pineda de Gyvez, "Resistance characterization for weak open defects," IEEE Design Test Comput., vol. 19 , no. 5, pp. 18-26, 2002.

[11] R. Rodríguez-Montañés, E. M. J. G. Bruls, and J. Figueras, "Bridging defects resistance measurements in a CMOS process," in Proc. Int. Test Conf., 1992, pp. 892-896.

[12] R. Glang, "Defect size distribution in VLSI chips," IEEE Trans. Semicond. Manuf., vol. 4, pp. 265-269, Nov. 1991.
[13] C. Hess, D. Stashower, B. E. Stine, L. H. Weiland, G. Verma, K. Miyamoto, and K. Inoue, "Fast extraction of defect size distribution using a single layer short flow NEST structure," IEEE Trans. Semicond. Manuf., vol. 14, pp. 330-337, Nov. 2001.

[14] C. Hess and L. H. Weiland, "Test structure for the detection, localization, and identification of short circuits with a high speed digital tester," in Proc. Int. Conf. Microelectron. Test Struct., 1992, pp. 139-144.

[15] C. Hess and A. P. Stroele, "Modeling of real defect outlines and parameter extraction using a checkerboard test structure to localize defects," IEEE Trans. Semicond. Manuf., vol. 7, pp. 284-292, Aug. 1994.

[16] K. Y.-Y. Doong, J.-Y. Cheng, and C. C.-H. Hsu, "Design and simulation of addressable failure site test structure for IC process control monitor," in Proc. Int.. Symp. VLSI-Technol., System, Applicat., 1999, pp. 219-222.

[17] A. V. S. Satya, "Microelectronics test structures for rapid automated contactless inline defect inspection," IEEE Trans. Semicond. Manuf., vol. 10, pp. 384-389, Aug. 1997

[18] C. H. Hawkins, J. M. Soden, E. I. Cole, Jr., and E. S. Snyder, "The use of light emission in failure analysis of CMOS ICs," in Proc. Int. Symp. Test. Failure Anal., 1995, pp. 55-67.

[19] K. Nikawa, C. Matsumoto, and S. Inoue, "Verification and improvement of the optical beam induced resistance change (OBIRCH) method," in Proc. Int. Symp. Test. Failure Anal., 1994, pp. 11-16.

[20] K. Nikawa, "How long can we succeed using the OBIRCH and its derivatives?," in Proc. Int. Test Conf., 2004, pp. 1443-.

[21] Y. Hamamura, T. Kumazawa, K. Tsunokuni, A. Sugimoto, and H. Asakura, "An advanced defect-monitoring test structure for electrical screening and defect localization," IEEE Trans. Semicond. Manuf., vol. 17, pp. 104-110, May 2004.

[22] R. E. Matick, Transmission Lines for Digital and Communication Networks. New York: McGraw-Hill, 1969.

[23] Semiconductor Industry Association, International Technology Roadmap for Semiconductors [Online]. Available: http://public.itrs.net

[24] S. Smith, A. J. Walton, A. W. S. Ross, G. K. H. Bodammer, and J. T. M. Stevenson, "Evaluation of sheet resistance and electrical linewidth measurement techniques for copper damascene interconnect," IEEE Trans. Semicond. Manuf., vol. 15, pp. 214-222, May 2002.

[25] S. Lakshminarayanan, P. Wright, and J. Pallinti, "Design rule methodology to improve the manufacturability of the copper CMP process," in Proc. Int. Interconnect Technol. Conf., 2002, pp. 9-101.

[26] R. Chang, Y. Cao, and C. J. Spanos, "Modeling the electrical effects of metal dishing due to CMP for on-chip interconnect optimization," IEEE Trans. Electron Devices, vol. 51, no. 10, pp. 1577-1583, 2004.

[27] R. Chang and C. J. Spanos, "Dishing-radius model of copper CMP dishing effects," IEEE Trans. Semicond. Manuf., vol. 18, no. 2, pp. 297-303, 2005.

[28] X. Zhang, L. He, V. Gerousis, L. Song, and C.-C. Teng, "Case study and efficient modelling for variational chemical-mechanical planarisation," IET Circuits Devices Syst., vol. 2, no. 1, pp. 30-36, Feb. 2008.

[29] T. H. Park, "Characterization and modeling of pattern dependencies in copper interconnects for integrated circuit," Ph.D. dissertation, Massachusetts Inst. of Technology, Cambridge, 2002.

[30] B. E. Stine, D. O. Ouma, R. R. Divecha, D. S. Boning, J. E. Chung, D. L. Hetherington, C. R. Harwoo, O. S. Nakagawa, and Oh. Soo-Young, "Rapid characterization and modeling of pattern-dependent variationin chemical-mechanical polishing," IEEE Trans. Semicond. Maf., vol. 11, pp. 129-140, Feb. 1998.

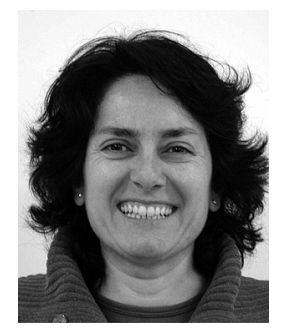

Rosa Rodríguez-Montañés received the M.S. degree from the Universitat de Barcelona, Barcelona, Spain, in 1988 and the Ph.D. degree in physical science from the Universitat Politècnica de Catalunya (UPC), Barcelona, in 1992.

Since 1994, she has been an Associate Professor with the Department of Electronic Engineering, UPC. During 2002, she spent her sabbatical leave with the Test Group at Philips Research (Eindhoven, The Netherlands). She is currently working on fault models, defect characterization, and defect diagnosis of digital nanometric CMOS technologies. 


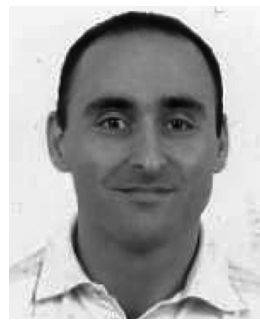

Daniel Arumí received the M.S. degree in industrial engineering and the Ph.D. degree in electronic engineering from the Universitat Politècnica de Catalunya (UPC), Barcelona, Spain, in 2003 and 2008, respectively.

He is currently in a Postdoctoral position in the Department of Electronic Engineering, UPC. His research interests include defect-based testing, fault modeling, and defect diagnosis.

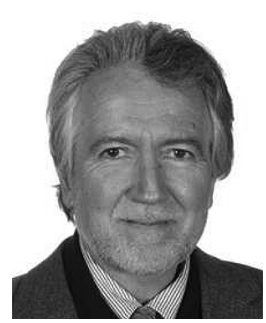

Joan Figueras (M'88) received the Ph.D. degree from Universitat Politècnica de Catalunya (UPC), Barcelona, Spain, and the M.Sc. and Ph.D. degrees from the University of Michigan, Ann Arbor.

He is currently with the Department of Electronics Engineering, UPC, where he has research and teaching responsibilities in the areas of electronics and digital- and mixed-signal design and test. His research interests are centered in emerging topics in low-power design and advanced test of electronic circuits and systems. He has an extensive publication record and has presented seminars and tutorials in professional meetings, NATO seminars on topics related to "Low Power Design" and "Quality in Electronics."

Dr. Figueras is currently an Editor of JETTA, was an Associated Editor of the IEEE TRANSACTIONS ON COMPUTER-AIDED DESIGN OF INTEGRATED CIRCUITS AND SYSTEMS, and is a member of the steering and program committees of several Test and Low Power Design Conferences.

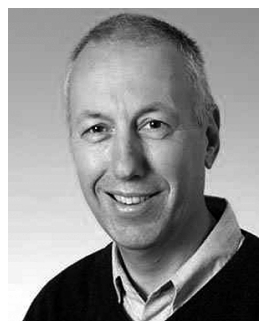

Willem Beverloo was born on January 1, 1948 in Zutphen, The Netherlands. After a study in electronics, he joined Philips Semiconductors in 1970 in different jobs as test and product engineer in transistors, diodes, standard IC's, ASIC's, and digital audio IC's. Since 1995, he has been a Senior Failure Analysis Engineer at NXP Semiconductors (spin off from Philips Semiconductors in 2006).

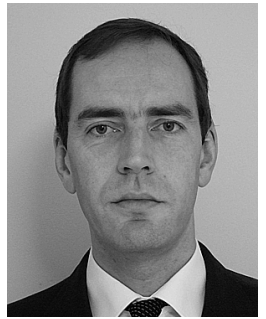

Dirk K. deVries (M'01) received the M.S. degree in technical physics from the University of Technology, Eindhoven, The Netherlands, in 1992, and the Ph.D. degree in physics from the Ruhr University, Bochum, Germany, in 1995.

Since 1996, he has been active in the field of semiconductor manufacturing yield. From 1996 to 2007, he held yield engineering, yield management, and yield consulting functions in Philips Semiconductors/NXP Semiconductors. Since 2007, he is PDF Solutions, Montpellier, France. Staff Engineer, Product Engineering Solutions with

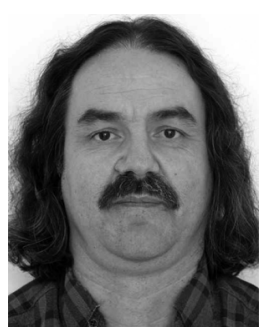

Stefan Eichenberger received the Ph.D. degree in science (physics) from the University of Zurich, Zurich, Switzerland.

$\mathrm{He}$ is a Senior Principal Engineer at NXP Semiconductors, Nijmegen, The Netherlands. His research interest includes defect based testing, diagnosis and yield learning. He joined NXP (then Philips) in 1993.

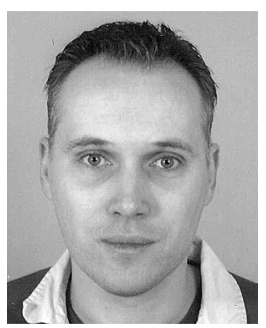

Paul A. J. Volf (M'93) received the M.S. degree in electrical engineering in 1994 and the Ph.D. degree in electrical engineering for his research work on data compression from the Eindhoven University of Technology, Eindhoven, The Netherlands, in 2002.

In 2000, he joined Philips Semiconductors, now NXP Semiconductors, where he started as DfM-Engineer, followed by product engineering positions in an internal waferfab and the automotive business line. Currently, he is a member of the New Product Introduction Team. His activities covr the process and product qualifications in internal specialty processes and advanced CMOS foundry processes. 